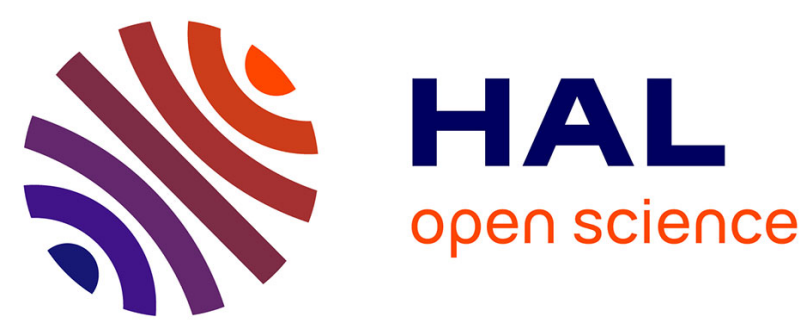

\title{
EXPERIMENTAL STUDY AND NUMERICAL SIMULATION OF HYDRODYNAMICS AND HEAT TRANSFER IN A COLD-WALL CVD REACTOR
}

H. Chehouani, B. Armas, C. Combescure, S . Benet, S. Brunet

\section{- To cite this version:}

H. Chehouani, B. Armas, C. Combescure, S . Benet, S. Brunet. EXPERIMENTAL STUDY AND NUMERICAL SIMULATION OF HYDRODYNAMICS AND HEAT TRANSFER IN A COLDWALL CVD REACTOR. Journal de Physique IV Proceedings, 1991, 02 (C2), pp.C2-175-C2-182. 10.1051/jp4:1991221 . jpa-00249808

\section{HAL Id: jpa-00249808 https://hal.science/jpa-00249808}

Submitted on 1 Jan 1991

HAL is a multi-disciplinary open access archive for the deposit and dissemination of scientific research documents, whether they are published or not. The documents may come from teaching and research institutions in France or abroad, or from public or private research centers.
L'archive ouverte pluridisciplinaire HAL, est destinée au dépôt et à la diffusion de documents scientifiques de niveau recherche, publiés ou non, émanant des établissements d'enseignement et de recherche français ou étrangers, des laboratoires publics ou privés. 
Colloque C2, suppl. au Journal de Physique II, Vol. 1, septembre 1991

\title{
EXPERIMENTAL STUDY AND NUMERICAL SIMULATION OF HYDRODYNAMICS AND HEAT TRANSFER IN A COLD-WALL CVD REACTOR
}

\author{
H. CHEHOUANI*, B. ARMAS* ${ }^{*}$ C. COMBESCURE., S. BENET ${ }^{* *}$ and \\ S. BRUNET** \\ "Institut de science et de Génie des Matériaux et Procédés, \\ CNRS, Odeilio, F-66120 Font Romeu, France \\ * Laboratoire de Physique Appliquee, Université Perpignan, \\ F-66860 Perpignan cedex, France
}

\begin{abstract}
A mathematical model including the NAVIER-STOKES and energy partial differential equations has been developed to predict the flow and temperature fields in a cold-wall CVD reactor. Particular attention is placed on understanding and explaining the influence of pressure on the hydrodynamics and heat transfer in the reactor. In order to validate the model predictions in the thermal aspect we used holographic interferometry to investigate the temperature gradients and to examine the thermal boundary layer thickness for several reactor inlet conditions. The comparison between the model predictions and experimental data shows good agreement.
\end{abstract}

\section{1-INTRODUCTION}

In the last decade chemical vapour deposition (CVD) has become a dominating deposition process in several industries. Despite its simplicity and versatility in the production of many thin solid films, the understanding of the CVD process is rather limited. The conventional approaches are based to a large extent on intuition and step-by-step improvement by methods of trial and error. These are time-consuming and expensive and their major inconvenience is their lack of generality. It is difficult to extend the results to different cases and especially to different reactor configurations. This becomes particularly crucial when one wants to transfer from laboratory study to industrial scale reactors. For this reason, both experimental and theoretical efforts of recent years have been aimed towards a more fundamental understanding of the relevant physicochemical mechanisms of the CVD technique /1-6/. The common objective of all workers in this area is to relate performance measures (e.g. deposition rate, film composition and uniformity) to operating conditions (e.g pressure, temperature, reactant concentration, gas flow and reactor geometry). Here, the development of mathematical models based simultaneously on fluid dynamics, kinetics and thermodynamics has played an important rôle. However, to incorporate all the physicochemical mechanisms in a general model is not realistic because of the complexity and diversity of situations that occur in a CVD process. So, the majority of the models proposed by different workers in this domain treat particular cases and favour either the chemical aspect or transport phenomena /7-11/. In fact, the individual study of each physicochemical process provides useful information for the understanding of the basic aspects of CVD processes. Our contribution deals with a theoretical and experimental study of hydrodynamics and 
heat transfer in the flowing gas phase within a large vertical axisymmetric cold-wall reactor. We focus on establishing the influence of the operating parameters on the temperature and velocity fields in the reactor.

\section{2- REACTOR GEOMETRY}

The cold-wall CVD reactor studied is a classical configuration for growth of pyrolitic carbon from the decomposition of methane [4]. It consists of a vertical stainless-steel cylinder with an interior diameter and height of $350 \mathrm{~mm}$. Relatively large, these dimensions lie between those of laboratory studies and those used in industry. The walls are water-cooled. Two Pyrex windows with a diameter of $160 \mathrm{~mm}$ are incorporated opposite one another in the vertical wall to permit optical analysis of the gas phase temperature by holographic interferometry. The graphite substrate, positioned on the reactor axis, is heated by high frequency induction. The water-cooled copper coil lies inside the reactor around the substrate. The gas supply is via either of two pipes situated in the upper and lower parts of the reactor.

\section{3-MATHEMATICAL MODEI,}

A complete model of the behaviour of a CVD reactor is based upon the momentum, energy and species equations governing the motion, heat and mass transfer. However, in experimental systems the reactives are often diluted $(55 \%)$ in a carrier gas $/ 11 \%$. Hence, the flow and heat transfer can be decoupled from the mass transfer and account taken only of this carrier gas. The temperature and velocity fields obtained in this way can be used for modelling different chemical reactions. It is important to note that this simplification cannot be made for the case of deposition reactions where molecules with very different sizes are involved.

\section{3-1 Model equations}

Thus, we have to deal with aerothermodynamic equations corresponding to the NAVIER-STOKES and energy equations. Assuming that there is a laminar, steady-state, incompressible, axisymmetric flow with variable gas properties these equations can be written in terms of dimensionless variables as follow :

\section{Continuity equation}

$$
\operatorname{div} e \vec{v}=0
$$

\section{Motion equation}

$$
(\varrho \vec{v} \cdot \overrightarrow{\operatorname{grad}}) \vec{v}=-\overrightarrow{\operatorname{grad}} P-1 / \operatorname{Re} \operatorname{div} \vec{\tau}-\mathrm{e} / \mathrm{Fr} \overrightarrow{\mathbf{k}}
$$

\section{Energy equation}

$$
(\operatorname{ecp} \vec{v} \overrightarrow{\operatorname{grad}}) \theta=1 / \operatorname{ReP}_{x} \operatorname{div}(\lambda \overrightarrow{\operatorname{grad}} \theta)
$$

where Re, $F r$ and $P_{r}$ are respectively the REYNOLDS number $V_{0} R_{S} \varrho_{0} / \mu_{0}$, FROUDE number $\mathrm{V}_{0}{ }^{2} /\left(\mathrm{gR}_{\mathrm{S}}\right)$ and PRANDTL number $\mu_{0} \mathrm{C}_{\mathrm{p}} / \lambda_{0}$. In these expressions, $e_{0}, \mu_{0}, \lambda_{0}, C_{p}$ and $v_{0}$ are respectively the gas properties and the mean velocity at the reactor inlet. $R_{\mathrm{s}}$ is the substrate radius and $g$ is the acceleration due to gravity. In this study, nitrogen is 
used as a carrier gas. The variation of its thermophysical properties as a function of temperature can be established using the kinetic theory of gases $/ 12 /$. In this way the viscosity $\mu$ and the thermal conductivity $\lambda$ can be put in a form facilitating numerical calculations as given in table 1 . The heat capacity $C p$ per unit mass is assumed to be constant. The ideal gas law is used to compute the density as a function of temperature. Thus we have :

\begin{tabular}{|c|c|c|c|}
\hline $\begin{array}{l}\text { Thermal conductivity } \\
\lambda\left(\mathrm{W} \cdot \mathrm{m}^{-1} \cdot \mathrm{K}^{-1}\right)\end{array}$ & $\begin{array}{c}\text { Viscosity } \\
\mu\left(\mathrm{kg} \cdot \mathrm{m}^{-1} \cdot \mathrm{s}^{-1}\right)\end{array}$ & $\begin{array}{l}\text { Heat capacity } \\
\left.\mathrm{C}_{\mathrm{p}} \text { (J. } \mathrm{kg}^{-1} \cdot \mathrm{K}^{-1}\right)\end{array}$ & $\begin{array}{l}\text { density } \\
\mathrm{e}\left(\mathrm{kg} \cdot \mathrm{m}^{-3}\right)\end{array}$ \\
\hline $2 \times 10^{-2}\left(\mathrm{~T} / \mathrm{T}_{0}\right)^{0 \cdot 6 \varepsilon}$ & $0.1797 \times 10^{-4}\left(\mathrm{~T} / \mathrm{T}_{0}\right)^{0.6841}$ & 1043 & $\mathrm{PM} / \mathrm{RT}$ \\
\hline
\end{tabular}

Table 1 Properties of nitrogen, $T_{0}=293 \mathrm{~K}$

The boundary conditions on the above set of equations and the geometrical dimensions for the calculation are given in terms of dimensionless variables in figure 1 . We emphasise that at the middle of the reactor the velocity and temperature fields are assumed to be fully developed. With this assumption, and the axisymmetry, the computational domain is reduced to a quarter of the reactor.

\section{3-2 Numerical solution}

The traditional formulation of the NAVIER-STOKES equations in terms of velocity and pressure $\left(V_{r}, V_{2}, P\right)$ has been replaced by an elliptical formulation in terms of stream function and vorticity $(\Psi, \varphi)$. These new variables are defined as follow :

$$
V_{x}=-\frac{1}{\mathrm{e} x} \frac{\partial \Psi}{\partial z} ; \quad V_{z}=\frac{1}{\mathrm{e} r} \frac{\partial \Psi}{\partial x} ; \quad \omega=\frac{\partial V_{x}}{\partial z}-\frac{\partial V_{z}}{\partial x}
$$

The momentum and energy equations are written in this elliptical

formalism as :

$$
\left\{\begin{array}{l}
\frac{\partial}{\partial r}\left(\frac{1}{\varrho r} \frac{\partial \Psi}{\partial r}\right)+\frac{\partial}{\partial z}\left(\frac{1}{\varrho r} \frac{\partial \Psi}{\partial z}\right)=-\omega \\
\frac{\partial}{\partial r}\left(-\frac{1}{r} \frac{\partial \Psi}{\partial z} \omega\right)+\frac{\partial}{\partial z}\left(\frac{1}{r} \frac{\partial \Psi}{\partial r} \omega\right)=\frac{1}{\operatorname{Re}}\left[\frac{\partial}{\partial r}\left[\frac{1}{r} \frac{\partial}{\partial r}(\mu r \omega)\right]+\frac{\partial^{2}}{\partial z^{2}}(\mu \omega)\right] \\
+\frac{1}{F r} \frac{\partial \varrho}{\partial r}+\frac{\partial e}{\partial r} \frac{\partial}{\partial z}\left(\frac{V_{r}^{2}+V_{z}^{2}}{2}\right)-\frac{\partial \varrho}{\partial z} \frac{\partial}{\partial r}\left(\frac{V_{r}^{2}+V_{z}^{2}}{2}\right) \\
C p\left(-\frac{1}{r} \frac{\partial \Psi}{\partial z} \frac{\partial \Theta}{\partial r}+\frac{1}{r} \frac{\partial \Psi}{\partial r} \frac{\partial \Theta}{\partial z}\right)=\frac{1}{\operatorname{ReP}_{r}}\left[\frac{1}{r} \frac{\partial}{\partial r}\left(r \lambda \frac{\partial \Theta}{\partial r}\right)+\frac{\partial}{\partial z}\left(\lambda \frac{\partial \Theta}{\partial z}\right)\right]
\end{array}\right.
$$

This formulation has many practical advantages (common formulation of equations, conservation of mass accounted for implicitly, elimination of pressure...). The above set of partial differential equations with the boundary conditions in terms of $(\Psi, \omega)$ is solved using a control volume-based finite differences method /11,13/. The computational domain is discretized into a non-uniform grid on which the solution field $(\Psi, \omega, \theta)$ is to be found. It consists of 2653 grid nodes in total in the radial and axial directions. The equations are integrated over the surface element surrounding each point of the mesh. Because of the non-Iinearity of the equations and the complexity of the terms to be integrated, a linear approximation of the dependant 
variables $(\Psi, \omega, \Theta)$ was necessary to facilitate the integration of the equations. The sets of equations resulting from the numerical scheme were solved iteratively using a GAUSS-SEIDEL method. The iteration procedure was terminated when the convergence criterion :

$$
\left|\frac{\varphi^{1}-\varphi^{1-1}}{\varphi^{1-1} \text { max }}\right| \leq 5.10^{-4} \quad \begin{array}{ll}
\varphi=\Psi, \omega \text { or } \theta \\
1 \text { : iteration number }
\end{array}
$$

was fulfilled at any node. To reach this criterion, 1000-2000 iterations were needed, taking $1-2 \mathrm{~h}$ of $\mathrm{CPU}$ time. All calculations were carried out on a NORSK-DATA ND 5700 minicomputer.

\section{3-3 Results}

\section{3-3-1 The flow and isotherms}

The results will be shown in terms of combined figures of flow streamlines (right-hand side) and isotherms (left-hand side). Figure 2 shows the flow patterns obtained with a flow rate $Q=2.8 \mathrm{scm}^{3} / \mathrm{s}$ of nitrogen. The temperatures of the wall and the substrate are respectively $T_{0}=20^{\circ} \mathrm{C}$ and $T_{s}=760{ }^{\circ} \mathrm{C}$ and the pressure is $P=45 \mathrm{kPa}$. The jet entering the reactor with an average velocity of $0.32 \mathrm{~cm} / \mathrm{s}$ widens slightly before strongly narrowing in accelerating towards the axis. This acceleration in the vicinity of the substrate is related to the steep temperature gradients. This motion leads to the creation of a large recirculating flow occupying pratically the entire reactor volume and causing the confinement of the jet. As the flow rate is small these recirculation cells are purely thermal ones and driven by natural convection effects. The phenomenon of recirculation can affect the residence time distribution of the reaction products and so the process yield. Moreover, the species can be trapped in the recirculations and isolated from the main flow $/ 7 /$. The strength of the recirculation can be measured by the ratio $c$ between the characteristic velocity of natural convection, $v_{c}$, in the vicinity of the substrate, and $v_{0}$ the average velocity of the inlet flow $/ 11 /$. Thus :

$$
\mathrm{V}_{c}=\frac{\mu}{\mathrm{QR}} \mathrm{Gr}_{\mathrm{S}}^{1 / 2} \Rightarrow \mathrm{C}=\frac{\mathrm{V}_{\mathrm{c}}}{\mathrm{V}_{0}}=\frac{\mathrm{Gr}}{\mathrm{Re}}
$$

where $G r=g R_{s}{ }^{3} \beta\left(T_{s}-T_{0}\right) e^{2} / \mu^{2}$ is the GRASHOF number. $C$ appears as the square root of the ratio of natural convection to forced convection ( $\mathrm{Gr} / \mathrm{Re}^{2}$ ) resulting from the scaling analysis. Looking at the expression for $\mathrm{C}$ in more detail shows that the recirculation is a function of flow rate, gas nature, pressure, the geometric parameter chosen as reference, and the temperature difference between the substrate and the wall.

The left hand side of the figure shows the predicted isotherms in the reactor. Here again we clearly observe the influence of natural convection effects on heat transfer in a cold-wall reactor. All the isotherms are localised near the substrate in a thermal boundary layer about $10 \mathrm{~mm}$ thick, which indicates the presence of steep temperature gradients.

\section{3-3-2 Effect of operating pressure}

In order to show the rôle of the operating pressure, we reduced its value by a factor of $100(P=450 \mathrm{~Pa})$ while the other parameters remained constant. Figure 3 shows the flow patterns and the isotherms obtained under these conditions. We note that the amount of 
recirculation decreased and the thermal boundary layer thickness increased considerably and became comparable to the reactor dimensions. It is easy to interpret this behaviour by a simple scaling analysis. Considering the variation of dimensionless numbers when the pressure is divided by $K$ with the same mass flow rate at the entrance we have :

case 1

$\left[\begin{array}{l}\mathrm{P}_{1} \\ \mathrm{e}_{1}=\frac{\mathrm{P}_{1} M}{\mathrm{RT}} \\ \mathrm{e}_{1} \mathrm{~V}_{1}=\mathrm{e}_{2} \mathrm{~V}_{2}\end{array}\right.$

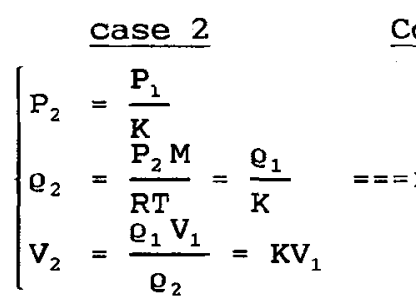

Comparison of dimensionless numbers

The dimensionless equations are similar in both cases except that the FROUDE number is multiplied by $\mathrm{K}^{2}$. Note that we can reach the same result by decreasing the gravity force, dividing $g$ by a factor $\mathrm{K}^{2}$ as obtained in micro-gravity situations. The simulation corresponding to a pressure divided by 100 is equivalent to $g \approx 10^{-3} \mathrm{~m} . \mathrm{s}^{-2}$. So, the diminution of pressture reduces the natural convection effects and therefore induces a lower recirculation and favours the heat diffusion as shown on the figure 3 .

\section{4-EXPERIMENTAL INVESTIGATION}

The main focus of this contribution is to investigate the temperature fields in the reactor which allows us to validate the model predictions in the thermal aspect. For this purpose, we developed an holographic interferometry set-up which we have described in detail in previous works $/ 11,14,15 /$. This non-destructive optical method has many practical advantages in comparison with other classical techniques used in heat transfer study $/ 1,16 /$. It allows us to follow "in-situ" the thermal behaviour of the vapour phase as a function of several operating conditions. For general information on holographic interferometry, the reader should consult the book of VEST 117/. Figure 4 shows an interferogram obtained with $45 \mathrm{kPa}$ of nitrogen and $\mathrm{TS}=760^{\circ} \mathrm{C}$. The thermal boundary layer is directly visualized from the interferogram. Observing the fringe pattern, this layer is delineated by the area where the fringes are deviated from the vertical finite fringe system where the temperature is ambiant. The thermal boundary layer form is approximately elliptic which is schematized in figure 5 by $\delta(r)$. Its thickness is maximal at the centre $\left(\delta(0)=\delta_{0}\right)$ and decreases towards the substrate edge which indicates the presence of a high thermal gradient in this region. $\delta_{0}$ is a function of several operating conditions. Fig. 6 shows its variation with the substrate temperature $T_{S}$, at an argon pressure of $66.6 \mathrm{kPa}$. We note that the thermal boundary layer thickness increases slowly with $T_{s}$ according to the law $\delta_{0}\left(T_{s}\right)=A . T_{s}{ }^{x}$ where the parameters $A$ and $x$ are given on figure 6. Moreover, it is important to note that for the substrate with a diameter of $25 \mathrm{~mm}\left(\Phi_{25}\right)$ the boundary layer thickness is 1.5 times bigger than that established around the substrate of diameter $40 \mathrm{~mm}\left(\Phi_{40}\right)$. Therefore, the temperature gradient is expected to be steeper in the latter case. This result can be explained by the expression for the GRASHOF number Gr, which can be taken as an excellent criterion for determining the thermal boundary layer thickness in natural convection dominated flows. Gr increases with the third power of the substrate radius $R_{s}$. So, the effects of natural convection increase with $R_{s}$ and therefore $\delta_{0}$ has a tendency to decrease. 
4-1 Effect of operating pressure

The operating pressure has more effect upon $\delta_{0}$ than does the temperature of the substrate. An increase in pressure is accompanied by a reduction in the thermal boundary layer thickness $\delta_{0}$, and consequently by an increase in the temperature gradient. The variation of $\delta_{0}$ as a function of pressure can be represented according to the law $\delta_{0}(P)=A$. Px and is shown in figure 7 .

\section{5- COMPARISON OF THE MODEL PREDICTIONS AND EXPERIMENTAL DATA}

Fig. 8 shows a comparison between predicted (right-hand side) and experimental (left-hand side) radial temperature distributions below the substrate. Globally, both cases give similar profiles: the temperature, approximately constant below the substrate, decreases rapidly from the edge with a steep gradient. The thermal boundary layer thickness predicted by the model and that visualized from the interferogram (fig.4) are of the same order. This result illustrates the agreement between the simulation and experiment.

\section{ACKNOWLEDGEMENTS}

This work has been supported by the "Societé Européenne de Propulsion-Division Propulsion à Poudre et Composites, F33165 Saint Médard en Jalles". The authors are grateful to JC. CAVALIER and JM. TOUSSAINT for useful discussions.

\section{REFERENCES}

/1/ COCHET G, MELLOTTEE H, DELBOURGO R, J. Electrochem. SOc. 125, $\mathrm{N}^{\circ} 3$, (1978) 487

12/ WAHL G, HOFFMANN R, Rev. int. Htes Temp.\& Refrac., Fr. 17 (1980) 7

/3/ BENET S, BERGE R, BRUNET S, CARLES C, ARMAS B, COMBESCURE C, PrOC. Third European Conf. on C.V.D. Edited by H.E. Hintermann, Neuchatel, Switzerland, (1980) 97

14/ GRANIER B, ARMAS B, BENET S, Proc of the sixth European Conf. on C.V.D. Edited by R.Porat (1987) 1

/5/ VINANTE C, DUVERNEUIL P, COUDERC J.P, J. PhYs. Colloque C5, Supplément $\mathrm{N}^{\circ} 5$, Tome 50, (1989) 35

/6/ KLEIJN C.R, VAN DER MEER Th.H, HOOGENDOORN C.J, J. Electrochem. SOC., $N^{\circ} 11,136(1989) 3423$

17/ FOTIADIS I, KIEDA S, JENSEN K.F, J.Crystal Growth N¹02 (1990)441

/8/. HOUTMAN C, GRAVES D.B, JENSEN K.F, J.Electrochem. Soc. 133, (1986) 961

19/ CHEHOUANI H, ARMAS B, BENET S, BRUNET S, J. Phys., Colloque C5 Supplément $\mathrm{N}^{\circ}$ 5, Tome 50, (1989) 47

$110 /$ LANGLAIS F, PREBENDE C, TARRIDE B, NASLAIN R, J. de PhYS., Colloque C5, Supplément $\mathrm{N}^{\circ} 5$, Tome 50, (1989) 93

/11/ CHEHOUANI $\mathrm{H}$, Thèse de doctorat Université de Perpignan, $\mathrm{N}^{\circ} 101 \mathrm{C}$, (1990)

/12/ ABE Y, KESTIN J, KHALIFA H.E, Rev.Gen.Therm. Fr., N²05 (1979) 11

/13/ GOSMAN A.D, PUN W.M, RUNCHAL A.K, SPALDING D.B, WOLFSHTEIN M, "Heat and mass Transfer in Recirculating flows" Academic Press, London, (1973)

114/ BENET S, BRUNET S, ARMAS B, ChEHOUANI H, Rev. Gén. Therm. Fr. $\mathrm{N}^{\circ} 322$, (1988) 525 .

/15/ BENET S, BRUNET S, ARMAS B, COMBESCURE C, CHEHOUANI H, 3eme Coll. Int. Visualisation et Traitement d'Images. Belfort. (1988) 52 .

/16/ BOUIX J., BERTHET M.P, DAZORD J, VNCENT H, PrO. Eight inter. conf. on CVD, Edit. The Electrochem. Soc. Pennington, (1981) 203

/17/ VEST C.H, "Holographic Interferometry" WILEY \& Son, New-York (1978) 

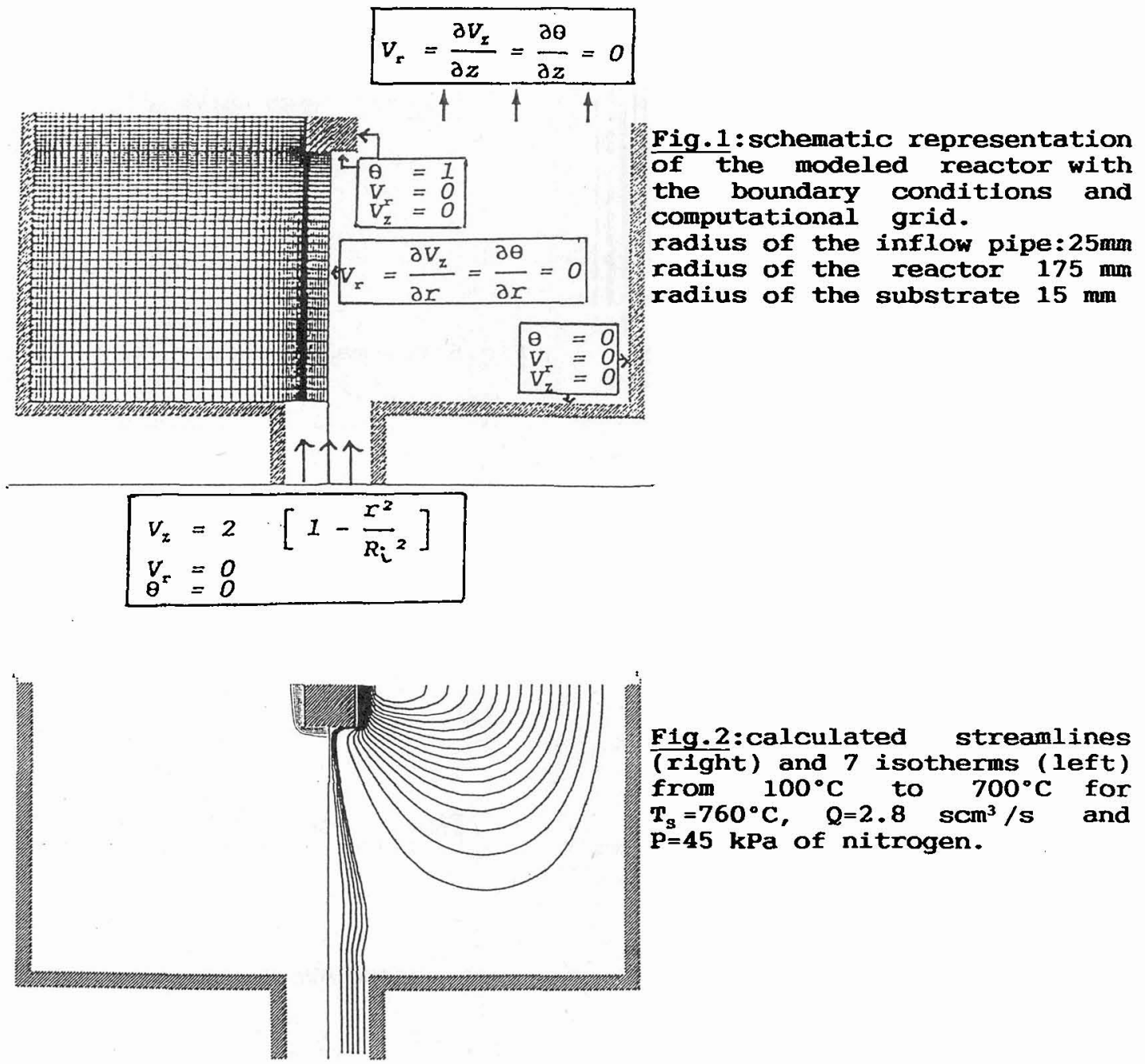

Fig.2:calculated streamlines (right) and 7 isotherms (left) from $100^{\circ} \mathrm{C}$ to $700^{\circ} \mathrm{C}$ for $T_{s}=760^{\circ} \mathrm{C}, Q=2.8 \mathrm{scm}^{3} / \mathrm{s}$ and $\mathrm{P}=45 \mathrm{kPa}$ of nitrogen.

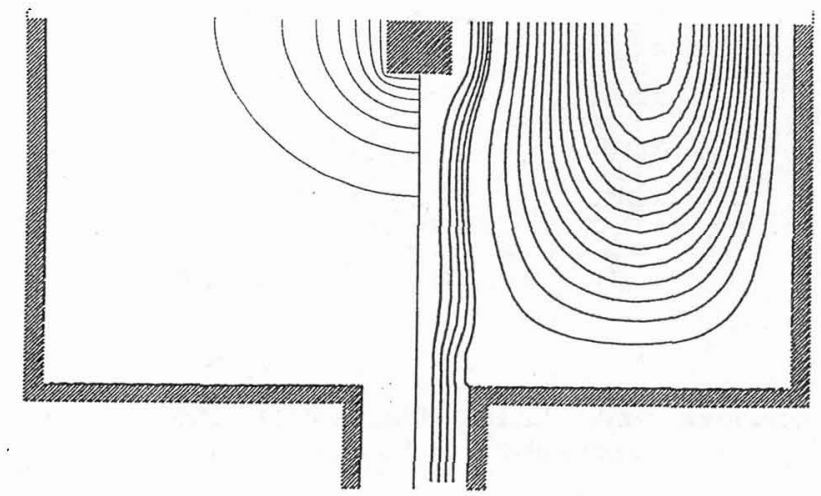

Fig.3:calculated streamlines (right) and 7 isotherms (left) from $100^{\circ} \mathrm{C}$ to $700^{\circ} \mathrm{C}$ for $T_{s}=760^{\circ} \mathrm{C}, \quad Q=2.8 \mathrm{scm}^{3} / \mathrm{s}$ and $\mathrm{P}=450 \mathrm{~Pa}$ of nitrogen. 


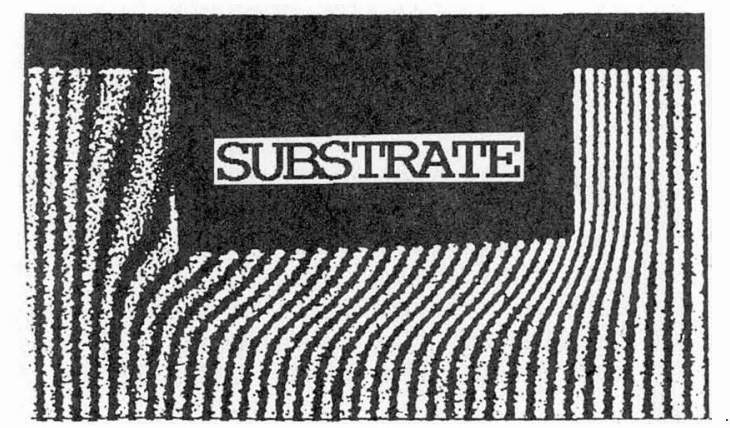

Fig.4: holographic interferogram

$\Phi_{30}$, nitrogen, $P=45 \mathrm{kPa}, T_{s}=760^{\circ} \mathrm{C}$

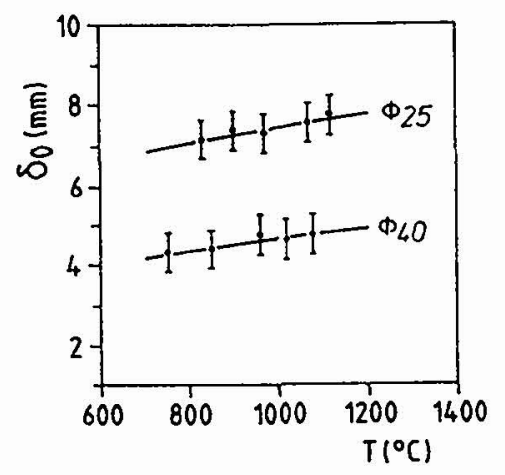

Fig.6 : $\delta_{0}=f\left(T_{s}\right)$ at $P=66.6 \mathrm{kPa}$ $\frac{\Phi_{25}}{\Phi_{2}} \dot{\delta}_{0}\left[T_{s}(K)\right]=1.454 \times T_{s} 0.2371 \mathrm{~mm}$ $\Phi_{40}: \delta_{0}\left[T_{s}(K)\right]=1.569 \times T_{s}^{0.3046} \mathrm{~mm}$

SUBSTRATE

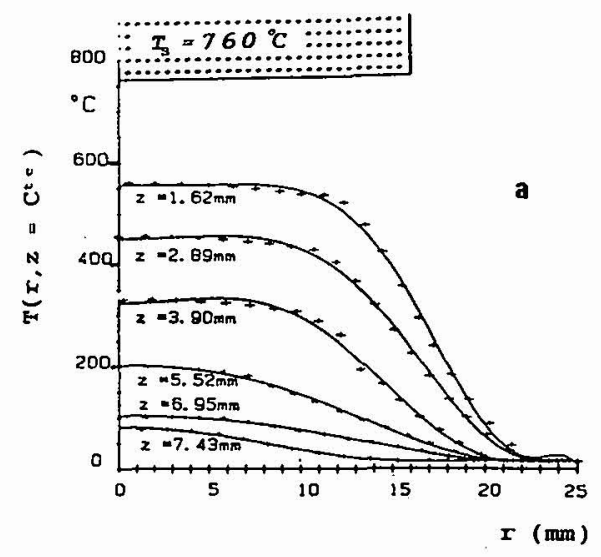

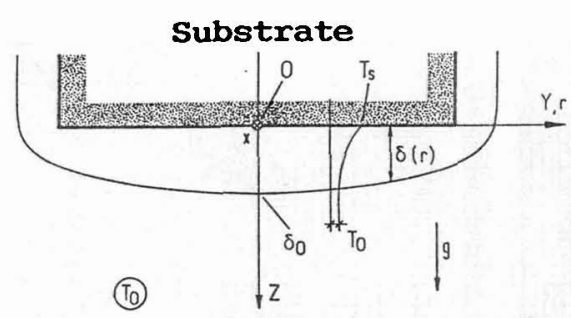

Fig.5: thermal boundary layer $\delta(r)$

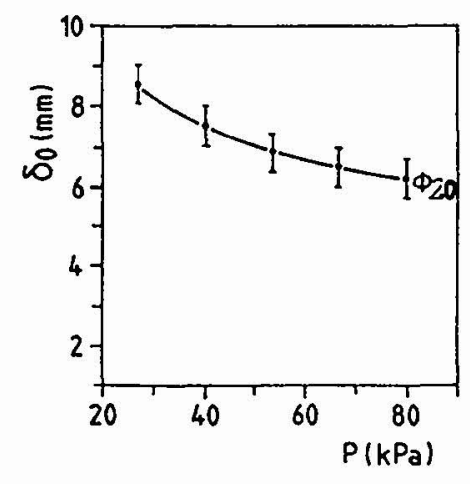

Fig.7: $\delta_{0}=f(P)$ at $T_{s}=850^{\circ} \mathrm{C}$ $\delta_{0}[\dot{P}(P a)]=176.5 \times P^{-0.2973} \mathrm{~mm}$

Fig.8 : radial distribution of temperature below the substrate $\Phi_{30}$, nitrogen, $P=45 \mathrm{kPa}, T_{s}=760^{\circ} \mathrm{C}$. a-Experiment, b-Simulation 